\title{
Toward the Valorization of Waste and Biomass
}

\author{
Ange Nzihou
}

\begin{abstract}
Valorization is the conversion of waste and biomass to energy, fuels and other useful materials, with particular focus on environmental indicators and sustainability goals. It is part of the larger endeavor of loopclosing. This topic is the object of cooperation between a large number of actors from various fields of engineering sciences, health and safety. In this paper, the relevance and the interest in this topic is discussed and supported with examples. The two examples proposed concern biomass and plastic films. Biomass has gained a tremendous interest during the ten last years and will be a subject for significant research progress in the future. The evolution of research in the production of biofuels from first, second and third generation biomass is discussed using thermal process. The second example concerns plastic films; valorization of plastics has been investigated for two decades already with relevant progress. However, this paper shows that there are still a number of issues to tackle and overcome for an efficient and effective valorization of plastic films. To improve and reach a significant valorization, integrated processes for proper separation, detection and classification of plastic film from industrial and commercial packaging waste are discussed. The paper also highlights the bottlenecks, barriers and challenging issues such as the emission of pollutants and greenhouse gases, energy efficiency, modeling, characterization, regulation and policy that will drive the development of this field in the future.
\end{abstract}

A. Nzihou $(\square)$

Ecole des Mines d'Albi-Carmaux, RAPSODEE, Campus Jarlard, 81013 Albi CT Cedex 09, France e-mail: ange.nzihou@mines-albi.fr

A. Nzihou

Université de Toulouse, 118 route de Narbonne,

31077 Toulouse Cedex, France
Keywords Valorization - Waste $\cdot$ Biomass $\cdot$ Challenges . Bottlenecks

\section{Introduction—waste and biomass valorization}

In recent years, an increasing number of research and development activities and efforts have been focused on the conversion of waste, biomass and various residues into energy, fuels and other useful materials, with emphasis on processes and practices that reduce emissions and integrate the life-cycle assessment of technologies and materials. This concept is known as valorization.

Until the 1990s development of technology was the main driver when dealing with waste and residues, the objective being the treatment of waste for disposal, storage and in some cases sorting. In the 1990s, depletion of raw materials and socio-economical concerns supported the direct recycling of waste and residues. However, the direct recycling approach is limited when waste/residues contain a significant amount of pollutants such as heavy metals and organics (VOC, PAH), and when the treatment process to remove/stabilize or destroy the pollutant generates emissions. Due to depletion of natural resources, increasing greenhouse emissions and awareness of the need for sustainable development in terms of safely reusing waste and biomass, the trend towards transformation of waste/biomass to valuable materials and energy i.e. valorization, is growing stronger.

This interest is manifested at European level via the significant increase in calls and projects in the field and is also observed in South America and in Asian Countries having a strong stake and large potential for research and development in these areas. In Japan, where the citizens are very sensitive to this issue, an environmental plan was set 
by the government in 2006 to promote all research and development leading to the beneficial reuse (valorization) of materials from waste and residues toward "zero-waste" in plastic, electronics, glass and fiber. Similar trend can be seen in China where the government launched in 2007 a 7 year framework programme on recovery of resources from wastes and residues, in particular biomass, sludges, wastewater and emissions in general. Countries such as Vietnam and Thailand are moving in the same direction. In South America, Brazil can be cited for its active funding of innovation and research for the production of biofuels from agricultural and paper industry waste and residues. Regarding the USA, the valorization approach is not fully up to speed though the waste-to-energy field is the object of significant activity and effort from research centres such as the Earth Engineering Center at Columbia University (New York City) and the Georgia Institute of Technology for the valorization of fibers and polymers.

More importantly, the field is one that is actively supported and engaged in by industry and government: The interest of industry is explained by the field's multi- and inter-disciplinarity, the focus on laboratory, pilot and full scale experiments showing the potentiality of the implementation of research dealing with the valorization of waste and biomass into energy and useful materials.

All this has been the inspiration for a new dedicated journal- "Waste and Biomass Valorization" with the strong support of various communities involved in these topics.

The existing competitive journals are more focused on treatment processes, characterization and assessment of hazardous materials and residues, whereas the end use of "products from waste and biomass (energy and/or materials)" is rarely emphasized. When the flow of materials and energy through industrial and consumer activities is considered, such as in the Industrial Ecology approach, discussion is limited to the impact on environment and how economic, political, regulatory, and social factors are tied into this, together with the transformation of natural resources. What is not fully considered in these journals is the crucial "end-of-pipe" processes that allow the recovery of materials and energy at both lab and pilot scale, processes which not only are of increasing importance in industry but are subject to legislation and regulation. This then is the focus of the rapidly expanding field of waste valorization.

\section{Example of Residue Streams and Challenges}

Research from various fields will be regularly published in this journal. Two important examples of research topics are Biomass and Plastics. Biomass has gained a tremendous interest during the ten last years and will be the object of significant research progress in the future. Meanwhile the Valorization of Plastics has been investigated for two decades already with tangible progress. However, there are still a number of issues to tackle and overcome. The two examples (non-exhaustive) presented give the overview of the stakes, barriers and challenges for the future.

Example 1 Trend in high temperature processes for valorization of biomass.

Biomass resources include primary, secondary, and tertiary sources. Primary biomass resources are produced directly by photosynthesis and are taken directly from the land. They include perennial short-rotation woody crops and herbaceous crops, the seeds of oil crops, and residues resulting from the harvesting of agricultural crops and forest trees (e.g., wheat straw, corn stover, and the tops, limbs, and bark from trees).

Secondary biomass resources result from the processing of primary biomass resources physically (e.g., the production of sawdust in mills), chemically (e.g., black liquor from pulping processes), or biologically (e.g., manure production by animals).

Tertiary biomass resources are post-consumer residue streams including animal fats and greases, used vegetable oils, packaging wastes, and construction and demolition debris.

The research into the field of second generation biomass has been strengthened since the first generation of biofuels (bioethanol from sugar cane and corn; biodiesel from rapeseed and sunflower oil) came into to a conflict with the food supply chain.

This negative phenomenon combined with various technical limitations of the bio-fuels in comparison to the common fossil fuels resulted in a slow take-up of first generation biomass in some cases. Another negative consequence might have been observed in the pharmaceutical industry as well, leading to an increase in drug prices. This has recently spurred research aimed at the production of bio-fuels from raw materials that do not compete with those common in the food market in particular. These fuels are known as "Second generation fuels" and they are generally produced from cellulosic materials. Their quality is higher than that of the common fossil fuels and they can substitute them at any range of dilution ratio $(0-100 \%)$ without any need for alterations to the fuel consuming engines or only minor changes [1].

From among the fossil fuel substitutes, the substitution of liquid fuels, which provide vehicle propulsion and industrial, domestic and other applications, is considered the most promising from an economical perspective, and the implementation of Biomass-to-Liquid (BTL) Fuel technologies is gaining great interest worldwide [2]. 
Various technologies exist for the production of energy or energy vectors (such as biomass to liquid) and materials. Let us consider the most common thermal process used today named the Fischer-Tropsch process developed in 1929 in Germany. This process is based on the catalytic synthesis of biomass-to-liquid liquor that can be transformed within a Fischer-Tropsch reactor into second generation Biodiesel from the synthesis gas (syngas) that is produced during the pyrolysis cracking of the organic matter. Syngas is a gas mixture composed of carbon monoxide, carbon dioxide and hydrogen. This process is currently subject to various modifications. These modifications make it possible to control the process yield, the composition of the synthesized fuel and its purity. Some of the developed Fischer-Tropsch modifications are already in stages of commercial implementation on large commercial scales [1]. Among the tangible modifications of this process one involves the addition of a Water Gas Shift Reactor [3], resulting in a high hydrogen-carbon ratio, in the efficient removal of the sulfur pollution from the product and of a high percentage of wax in the hydrocarbon pyrolysis products. The wax fragment being used in a hydro-cracking process and a liquid diesel product with a high degree of purity and quality (small amounts of sulfur and aromatic hydrocarbons) is obtained with a high production yield.

Nevertheless, the pyrolysis and gasification are autotherm processes and the energy balance requires some improvements. Research toward the use of allotherm energy pyrolysis and gasification using plasma technologies and solar energy is a particularly promising field for research to improve the valorisation of waste and biomass [4]. A factor in overcoming this is illustrated research focusing on Concentrating-Solar Biomass Gasification Process for a 3rd Generation Biofuel [5]. This is a new concept for producing synfuel from biomass using concentrated solar energy as its main energy source. The concept's key feature is the use of high-temperature from a solar concentrating tower to drive the chemical process of converting biomass to a biofuel, obtaining a near-complete utilization of carbon atoms in the biomass. This is advantageous since it allows production of an easy to handle fuel with near-zero $\mathrm{CO}_{2}$ emission and has reduced land-use requirements compared to first and second generation biofuels. This is a promising field in research for the sustainable valorisation of waste and biomass.

Besides the thermal technologies (gasification, pyrolysis, combustion, etc....), the exploitation of biogas can pass through the fermentation of some organic residues, also coming from agricultural or food processing processes, in a fermenter, a reactor in which bacteria or enzymes reduce the matter to methane and $\mathrm{CO}_{2}$. One of the most important factors is the best choice of the enzymes or methane bacteria to be used in the fermentation reactor. Some of these enzymes and bacteria are known to specific materials, such as dairy by-products, rice and cereal residues, sewage sludge, mature sewages, diary sludge, organic fraction of municipal solid waste, etc., while some other best performer methane bacteria are not efficient for olive pomace, wine residues, fruit and vegetable organic wastes, sunflower and rapeseed vegetable oil extraction residues.

Example 2 Trend in the Valorization of Plastic Films.

Plastics meet the demands of society by enabling the affordable manufacture of numerous products. Their low density and consequently light weight, strength, flexibility and durability are some of the properties which make them so versatile. In 2006 global plastic production reached 245 million tonnes. In Western Europe alone it was 43.5 million tonnes of which $38 \%$ were consumed by the packaging sector. However, the technological development in plastics has fallen short of fulfilling the promises of recycled products. Although common plastics are recoverable and recyclable (e.g. PET, $P P$ and $\mathrm{HDPE}$ ), they need to be perfectly separated and sorted from plastic waste in order to get a high-quality final product with excellent mechanical properties, and therefore, being able to compete with plastic virgin materials in price and in mechanical properties [6-8].

The packaging industry generates annually a large amount of plastic waste made up of a mixture of different kinds of polymers. When a proper separation and later classification is not possible, the residues end up in landfills and therefore canceling out possible benefits.

While well over $90 \%$ of crates and boxes are recycled, the rates for the remaining mixed plastics are still lowbelow $10 \%$. Recycling for post-consumer plastics has been increasing at a rate of $7 \%$ per year, which means a total amount of 12 million tonnes recycled in 2007 and about 13 million tonnes in 2008 . However, the recycling rate for film is still very low, so there is a need for promoting recycled film in order to achieve statistics similar to the plastic post-consumer situation. Furthermore, prices of recycled products are predictable in contrast with those of virgin materials. In total, the European average recycling rate for post-consumer packaging plastic was $27.4 \%$ in 2006, varying slightly from country to country. Sixty-one percentage of the plastic film collected in EU is discarded. That could be used as raw material for developing new products (bags, urban furniture or pipes, among others) or enhancing current applications (as energetic valorization) because film could be sorted from the rest of the residues. This waste can be regarded as a severe economic loss.

Currently there are techniques for separating films from rigid plastic materials (such as PET bottles) due to the differences in their physical properties (e.g. density, color or weight). The majority of current techniques such as 
grinding can damage the film's properties having negative impacts on the later valorization of the product. The film needs to be cut by an impact blade that will not cause the reduction of its plasticity and strain capacity. But this separation is not selective according to type (color, composition, etc.) of film so usually all films end up mixed in a waste treatment plant. Other techniques such as sink floating $[8,9]$ are interesting but present serious difficulties in separating plastics with similar densities, like polyolefins films (Polypropylene, PP; High density and Low density Polyethylene, HDPE and LDPE). Moreover these methods present environmental problems due to the wastewater treatment process needed.

To improve and reach a significant valorisation of film plastic, integrated processes for proper separation, detection and classification of plastic film from industrial and commercial packaging waste are needed. A significant effort in research is in progress worldwide for the development of separation techniques and detection to increase the amount of plastic film to be valorised

However, significant progress has been made in the field of automated sorting systems employing detection systems (Near Infrared Systems NIS, X-Ray and visible light) or a combination of them, to identify different types of plastics, and sorting them either by resin type, shape, colour, or by physical and chemical properties. Macro-sorting technologies are used for whole plastic materials (e.g. bottles) and micro-sorting for granulated materials. These detection methods show a number of limitations according to their detection range. Progress in research and development is expected in the near future to improve the method with immediate effect on the sorting and separation processes and the valorisation of this fraction of plastic materials.

\section{Bottlenecks for Efficient Valorization}

Despite the many processes available, there are various unsolved issues to be addressed when dealing with the valorization of biomass and waste.

- The issue of emission of pollutants and greenhouse gases is of particular concern. Raw materials may contain elements such as chlorine, sulfur and heavy metals that could affect the quality of the syn-gas produced. In such cases, a special abatement technology has to be used to reduce the content of pollutants $\left(\mathrm{H}_{2} \mathrm{~S}, \mathrm{HCl}\right.$, metals) within the syn-gas avoiding the corrosion of the engines.

- Energy efficiency (allotherm and authotherm) of the processes.

- Modelling is another field where research progress is still high. Models taking into account all the influencing factors in order to predict and scale (up or down) the working conditions and economical feasibility and efficiency to use a wide range of available feedstock, and their suitability for the production of biofuel and materials need to be developed.

- Characterization: scientific investigation presenting accurate data on the composition and characteristics of the materials should be a basic prerequisite for any scheme in waste and biomass conversion. The possibilities of predicting the availability of raw materials and their suitability to the facilities will have a significant importance. The prediction data are of crucial importance in any assessment of the technical and economic feasibility of operating the valorization facilities.

- Regulation and Policy: The environmental policy set in the 1990s is still in force and is mainly focused on disposal and storage of waste and residues into landfill. This regulation no longer reflects current knowledge (thanks to progress in research in recent years) of the beneficial reuse of waste and biomass as opposed to landfill. The ongoing research and development on the conversion of these residue streams will contribute to improve and/or adapt the existing policy and regulation to favour all environmentally friendly valorization and establish best available technologies.

\section{Journal Overview}

This journal publishes cutting-edge research and development reports on waste and biomass to energy and useful materials with emphasis on processes and practices that reduce emissions. Research on the characterization of fuels and materials production as well as on the development of characterization techniques will be welcome key issues. Issues such as life cycle and risk assessment, health and safety impact assessment, decision-making, legislation and education will also be vigorously addressed.

Particular attention will be paid to the multidisciplinary and in bridging various fields of engineering (chemical, civil, environmental and materials) dealing with the valorisation of waste, biomass and various residues for the sustainable production of energy and useful materials.

High quality research articles, reviews, case studies (both pilot-plant and full-scale) will be considered for publication.

\section{References}

1. Demirbas, A.: Biodiesel-a realistic fuel alternative for diesel engines. Springer Verlag London Ltd, London (2008) 
2. Bridgwater, A.V., Peacocke, G.V.C.: Fast pyrolysis processes for biomass. Renew. Sustain. Energy Rev. 4(1), 1-73 (2000)

3. Lappas, A.A., Bezergianni, S., Vasalos, I.A.: Production of biofuels via co-processing in conventional refining processes. Catal. Today 145, 55-62 (2009)

4. Kezelis, R., Mecius, V., Valinciute, V., Valincius, V.: Waste and biomass treatment employing plasma technology. High Temp. Mater. Process. 8(2), 273-282 (2004)

5. Hertwich, E.G., Zhang, X.: Concentrating-solar biomass gasification process for a 3rd generation. Biofuel. Environ. Sci. Technol. 43(11), 4207-4212 (2009)
6. Burat, F., Güney, A., Olgaç Kangal, M.: Selective separation of virgin and post-consumer polymers (PET and PVC) by flotation method. Waste Manage. 29(6), 1807-1813 (2009)

7. Tam, V.W.Y., Tam, C.M.: A review on the viable technology for construction waste recycling Resources. Conserv. Recycl. 47(3), 209-221 (2006)

8. Howell, S.G.: A ten year review of plastics recycling. J. Hazard. Mater. 29(2), 143-164 (1992)

9. Shent, H., Pugh, R.J., Forssberg, E.: A review of plastics waste recycling and the flotation of plastics. Resour. Conserv. Recycl. 25(2), 85-109 (1999) 